\title{
Effect of Proximal Muscle Strengthening on Distal Muscle Facilitation in Guillain Barre Syndrome
}

\author{
Ankeeta Rajendra Vispute1, Suraj Bhimrao Kanase² \\ 1Department of Physiotherapy, Krishna Institute of Medical Sciences (Deemed to Be \\ University), Karad, Maharashtra, India. ${ }^{2}$ Department of Physiotherapy, Krishna Institute of \\ Medical Sciences (Deemed to Be University), Karad, Maharashtra, India.
}

\section{ABSTRACT}

\section{BACKGROUND}

In Guillain Barre Syndrome (GBS), there is symmetrical muscle weakness which ranges from mild weakness to severe palsy of all limbs. The motor symptoms start distally and move proximally. Proximal muscle weakness is primary and common factor in GBS. To overcome the weakness, one has to strengthen the muscle. Muscle activity of proximal segment is necessary for activation of distal segment. In fact, stable activity of distal parts needs controlling of the proximal parts. As distal muscle weakness is a major problem in post GBS individuals, they need to be facilitated with the help of proximal muscle strengthening.

\section{METHODS}

After obtaining the ethical committee clearance an experimental study was conducted among a total of $30 \mathrm{GBS}$ subjects selected through convenience sampling. OPD subjects were given proximal muscle strengthening for 6 weeks. Each subject was examined by modified sphygmomanometer test (MST) and functional independence measure scale (FIMS) before and after the study.

\section{RESULTS}

Result was calculated by using MST and FIMS. Exercises showed extremely significant difference on MST $[p=0.0001, t=11.924]$ on handgrip strength, $[p$ value $=0.0001) t$ $=12.334$ ] on plantar flexion, $[\mathrm{p}$ value $=0.0001, \mathrm{t}=9.558$ ] on dorsiflexion. FIMS [p value $=0.0001, t=25.699]$ extremely significant difference was seen.

\section{CONCLUSIONS}

Proximal muscle strengthening is found to be effective for distal muscle facilitation in Guillain Barre Syndrome.

\section{KEY WORDS}

Guillain Barre Syndrome, Proximal Muscle Strengthening, Distal Muscle Weakness, Functional Mobility, Modified Sphygmomanometer Test, Functional Independence Measure Scale
Corresponding Author: Dr. Suraj Bhimrao Kanase. Krishna College of physiotherapy, Krishna Institute of Medical Sciences Deemed to be University, Near Dhebewadi Phata, Malkapur, Karad - 415110, Maharashtra, India E-mail: drsurajkanase7@rediffmail.com

DOI: $10.14260 / \mathrm{jemds} / 2020 / 595$

How to Cite This Article:

Vispute AR, Kanase SB. The effect of proximal muscle strengthening on distal muscle facilitation in Guillain Barre Syndrome. J Evolution Med Dent Sci 2020;9(37):2741-2745, DOI: $10.14260 /$ jemds/2020/595

Submission 10-06-2020,

Peer Review 03-08-2020,

Acceptance 10-08-2020,

Published 14-09-2020.

Copyright (c) 2020 JEMDS. This is an open access article distributed under Creative Commons Attribution License [Attribution 4.0 International (CC BY 4.0)] 


\section{BACKGROUND}

Guillain-Barré Syndrome (GBS) is defined as an acute inflammatory demyelinating polyradiculoneuropathy that affects nerve roots and peripheral nerves leading to motor neuropathy and flaccid paralysis. ${ }^{1}$ GBS is usually monophasic immune mediated disorder. ${ }^{2}$ Symmetrical motor paralysis occurs due to the demyelination of peripheral nerve axons, which gradually progress and ascends from the lower extremities and leads to tingling, burning sensations and areflexia. ${ }^{3}$ It usually follows viral infections including EpsteinBarr virus, Campylobacter jejuni, cytomegalovirus, mycoplasma pneumonia and influenza virus. ${ }^{4}$ Symptoms usually peak in 2 to 4 - week time period followed by a recovery period that can extend from week to months ${ }^{5}$ After the plateau phase of 2 - 4 weeks, recovery begins with gradual resolution if paralysis that last $1-2$ years. ${ }^{6}$

Motor symptoms starts distally and move proximally, first there is involvement of lower limb than upper limb then progressively it involves trunk and cranial muscles. variable symptom is pain, tenderness occurs on deep pressure specially to motor points in muscle and nerve trunk and also parasthesia.7 Annual incidence is 1 - 2 per 100,000 worldwide. ${ }^{8,9}$ Men are more likely to be affected than Women with the ratio of 2:1.10 Younger population is the most common population that gets affected (30 - 50 years), although it can occur in any age..$^{4,11}$

\section{Classification}

There are other variants of Guillain Barre Syndrome. Commonly recognised variants of GBS include those with axonal forms, variants based on particular fibre type involvement (sensory or autonomic) and Miller Fisher syndrome. ${ }^{2}$

Axonal is divided into Acute Motor Axonal Neuropathy and Acute Motor Sensory Axonal Neuropathy

1. Acute motor axonal neuropathy (AMAN) - In AMAN there is only motor weakness without sensory symptoms or signs. Here sensory nerve conduction studies are normal and motor nerve studies are low or absent.

2. Acute motor sensory axonal neuropathy (AMSAN) - There is involvement of sensory nerves with severe residual disability. It affects adults rather than children.

Miller Fisher Syndrome is a triad of acute ophthalmoparesis, ataxia, and areflexia, now known as Fisher's syndrome. Clinical features include - facial weakness, oropharyngeal weakness, internal ophthalmoparesis and central nervous system involvement. MFS is generally, selflimiting condition with good prognosis. ${ }^{2}$

\section{Pathophysiology}

Immune system begins to attack the body itself, due to involvement autoimmune responses. Cross reaction is caused between immune responses and the neural tissue. GBS primarily involve the Schwann cell that affects the spinal roots and nerve, this results in segmental demyelination of the nerve process and later proliferation of the Schwann cell. The axon remains intact and conduct an impulse with reduced velocity, later axonal degeneration may occur in some patients which cause complete conduction block. The peripheral nervous system is associated with perivascular lymphocytic inflammatory exudates. Recovery occurs by axonal regeneration and remyelination of peripheral axons. Internodal distance is less because of myelin sheath is thinner and there is increase in number of nodes of Ranvier. Nerve conduction velocity is within the normal limits in less severe cases. However, conduction velocity may be permanently abnormal, where axonal damage are occur. ${ }^{12}$

Normal physiotherapy treatment approach includes correct positioning in bed, hydrotherapy, isometrics, free exercises and aerobic exercises. ${ }^{13}$ These exercises concentrate more on distal extremities without focusing on proximal control. In GBS, Motor symptoms starts distally and move proximally, first, there is involvement of lower limb than upper limb then progressively it involves trunk, where proximal muscles are largely affected than distal muscle. Muscle activity of proximal parts is necessary for activation of distal parts. In fact the stable activity of distal parts needs controlling the proximal parts. ${ }^{14}$ Proximal muscle strengthening exercises that includes open kinetic chain (OKC) and closed kinetic chain (CKC) exercises which further develop muscle strength and proximal stability i.e. stability of joints closest to the body such as shoulder joint and hip joint. Proximal muscles of upper limb concentrate on triceps brachii, biceps brachii, deltoids, pectoral is major and minor and lower limb focuses on muscles of hip musculature mainly gluteus Maximus, gluteus medias, quadriceps and hamstrings. ${ }^{15}$ In Guillain Barre syndrome, physical impairments are more prone to disability. Muscle weakness, paralysis and numbness can all affect the ability to move, stand and walk which makes patient highly dependent. Normal growth and development is believed to progress from proximal control to distal control. As Distal muscle weakness is major problem in post GBS individuals they are needed to strengthen in order to improve functional mobility, quality of daily living activities. ${ }^{16}$ Proximal muscle strengthening can be beneficial in improving the strength of distal muscle. ${ }^{17}$

\section{METHODS}

It was an experimental study carried out among subjects with GBS with distal muscle weakness and those who satisfied the inclusion criteria. The inclusion criteria were - diagnosed cases with Guillain Barre Syndrome, subjects with Manual Muscle Testing (MMT) grade 2 and above for proximal muscles. Subjects were excluded if they were Ventilator dependent, Recent Upper limb and lower limb Fractures, Concomitant conditions (cardiovascular diseases, malignancy) and severely fatigue subjects.

\section{Intervention}

This study was conducted in Krishna Hospital, Karad with a sample size of 30 (20 males / 10 females) after getting ethical approval from the institutional ethical committee. According to Alexandrescu R, Siegert RJ et al. $\mathrm{SD}=23, \mathrm{X}=30, \sum=0.03$ was taken in consideration and Sample size was calculated by the formula $\mathrm{n}=4 \mathrm{SD}^{2} /\left[\left(\mathrm{X} \times \sum\right)^{2}\right]$. Subjects who were willing to participate in the study were included in the study by using consecutive sampling method for OPD subjects and 
convenience sampling method for IPD subjects. Before proceeding to intervention, a written consent had been taken from them. The intervention had been given for 6 weeks and treatment will be given 5 times a week. Proximal muscle strengthening exercises was given for upper limb and lower limb that included exercises with assistance followed by active exercises and then progressively with resistance. Pre and post tests were done using the outcome measures modified sphygmomanometer test ${ }^{18,19}$ for assessing distal muscle strength and functional independence measure scale ${ }^{20,21}$ for functional mobility in subjects with Guillain barre syndrome.

\section{Statistical Analysis}

Statistical analysis was performed using Instat software. Comparison was done within the group by using paired ' $t$ ' test. The result were presented as mean \pm standard deviation (SD).

\section{RESULTS}

Total 30 patients were included in the study. Out of which 20 were male and 10 were female. Primary outcomes used for the result were modified sphygmomanometer test and functional independence measure scale which were taken before and after the study. Paired ' $t$ ' test was used to analyse the effect of proximal strengthening exercises on distal muscle facilitation.

Modified Sphygmomanometer test showed extremely significant improvement in right handgrip strength with $\mathrm{p}$ value of 0.0001 . Pre interventional value of mean and standard deviation was $32.26 \pm 6.512$ and post interventional value of mean and standard deviation was $77.26 \pm 25.507$ and also showed extremely significant improvement in left handgrip strength that is $\mathrm{p}$ value of 0.0001 . Pre interventional value of mean and standard deviation was $31.933 \pm 6.00$ and post interventional value of mean and standard deviation was $80.133 \pm 26.673$ (Table 1 )

MST showed extremely significant improvement in right lower limb (plantar flexion) with $\mathrm{p}$ value of 0.0001 . Pre interventional value of mean and standard deviation was 32.6 \pm 7.262 and post interventional value of mean and standard deviation was $80.93 \pm 26.795$ and also showed extremely significant improvement in left lower limb (plantar flexion) with $p$ value of 0.0001 . Pre interventional value of mean and standard deviation was $34.53 \pm 6.68$ and post interventional value of mean and standard deviation was $82.333 \pm 22.997$ (Table 2)

MST showed extremely significant improvement in right limb (dorsiflexion) with p value of 0.0001 . Pre interventional value of mean and standard deviation was $26.86 \pm 5.399$ and post interventional value of mean and standard deviation was $57.6 \pm 21.626$ and also showed extremely significant improvement in left lower limb (dorsiflexion) with $\mathrm{p}$ value of 0.0001 . Pre interventional value of mean and standard deviation was $27 \pm 5.298$ and post interventional value of mean and standard deviation was $58.8 \pm 21.474$ (Table 3 ).

Functional independence measure scale showed extremely significant improvement with $p$ value of 0.0001 . Pre interventional value of mean and standard deviation was $76.96 \pm 6.305$ and post interventional value of mean and standard deviation was $115.266 \pm 9.040$ (Table 4).

\begin{tabular}{|cccc|}
\hline & $\begin{array}{c}\text { Pre-Training } \\
\text { Mean } \pm \text { SD }\end{array}$ & $\begin{array}{c}\text { Post-Training } \\
\text { Mean } \pm \text { SD }\end{array}$ & P Value \\
MST (Right Handgrip) & $32.26 \pm 6.512$ & $77.26 \pm 25.507$ & $<0.0001$ \\
MST (Left Handgrip) & $31.933 \pm 6.00$ & $80.133 \pm 26.673$ & $<0.0001$ \\
\hline \multicolumn{4}{|c|}{ Table 1. Comparison of Mean and SD Pre- and Post-Treatment } \\
of MST for Right and Left Upper Limb & \\
\hline \multicolumn{4}{|l|}{$\begin{array}{l}\text { Pre and post treatment values shows that there is extremely significant difference } \\
\text { in MST for right and left handgrip (<0.0001) }\end{array}$} \\
\hline
\end{tabular}

\begin{tabular}{|lccc|}
\hline & $\begin{array}{c}\text { Pre-Training } \\
\text { Mean } \pm \text { SD }\end{array}$ & $\begin{array}{c}\text { Post-Training } \\
\text { Mean } \pm \text { SD }\end{array}$ & P Value \\
MST (Right Plantarflexion) & $32.6 \pm 7.262$ & $80.93 \pm 26.795$ & $<0.0001$ \\
MST (Left Plantarflexion) & $34.53 \pm 6.68$ & $82.333 \pm 22.997$ & $<0.0001$ \\
\hline \multicolumn{4}{|c|}{ Table 2. Comparison of Mean and SD Pre- and Post-Treatment } \\
of MST for Right and Left Plantar Flexion & \\
\hline $\begin{array}{l}\text { Pre and post treatment values shows that there is extremely significant difference } \\
\text { in MST for right and left plantarflexion }(<0.0001)\end{array}$ & \\
\hline
\end{tabular}

\begin{tabular}{|lccc|}
\hline & $\begin{array}{c}\text { Pre-Training } \\
\text { Mean } \pm \text { SD }\end{array}$ & $\begin{array}{c}\text { Post-Training } \\
\text { Mean } \pm \text { SD }\end{array}$ & P Value \\
\hline MST (Right Dorsiflexion) & $26.86 \pm 5.399$ & $57.6 \pm 21.626$ & $<0.0001$ \\
MST (Left Dorsiflexion) & $27 \pm 5.298$ & $58.8 \pm 21.474$ & $<0.0001$ \\
\hline Table 3. Comparison of Mean and SD Pre- and Post-Treatment \\
of MST for Right and Left Dorsiflexion
\end{tabular}

\begin{tabular}{|c|c|c|c|}
\hline & $\begin{array}{l}\text { Pre-Training } \\
\text { Mean } \pm \text { SD }\end{array}$ & $\begin{array}{l}\text { Post-Training } \\
\text { Mean } \pm \text { SD }\end{array}$ & P Value \\
\hline FIMS & $76.96 \pm 6.305$ & $115.266 \pm 9.040$ & $<0.0001$ \\
\hline \multicolumn{4}{|c|}{$\begin{array}{l}\text { Table 4. Comparison of Mean and SD Pre-and Post-Treatment } \\
\text { of Functional Independence Measure Scale }\end{array}$} \\
\hline \multicolumn{4}{|c|}{$\begin{array}{l}\text { Pre and post treatment values shows that there is extremely significant difference } \\
\text { in functional independence measure scale }(<0.0001)\end{array}$} \\
\hline
\end{tabular}

\section{DISCUSSION}

Guillain Barre Syndrome (GBS) is an acute, monophasic, symmetrically progressive, ascending demyelinating polyneuropathy characterized by rapidly evolving symmetrical limb weakness, areflexia, absent or mild sensory signs, and variable autonomic disturbances. ${ }^{22}$ Symptoms usually peak in 2 to 4 - week time period followed by a recovery period that can extend from week to months. ${ }^{6}$ The motor symptoms start distally to proximally involving lower limbs, preceding that of upper limb and can progress to trunk where proximal muscles goes into major weakness followed by distal muscles. ${ }^{7}$ Muscle activity of proximal parts is necessary for activation of distal parts and the stable activity of distal parts needs controlling the proximal parts. ${ }^{14}$

In GBS, there is delayed recovery in distal parts of limbs. Normal Motor development is believed to progress from proximal control to distal control and gross movements to fine movements. ${ }^{23}$ As distal muscle weakness is a major problem in GBS can be facilitated with the help of proximal muscle strengthening. Physical impairments in GBS are most disabling. Muscle weakness, paralysis and numbness makes patient highly dependent. Proximal muscle strengthening is helpful for making patient functionally independent and improving functional mobility.

In the present study, proximal muscle strengthening exercises were given which include exercises with assistance followed by active exercises and then with progressively resistance. There was significant improvement in distal muscle strength and functional mobility after the entire treatment programmed. The measurement taken by modified 
sphygmomanometer and functional independence measure scale

Some previous study evaluated physical therapy and functional motor recovery in patient with Guillain Barre Syndrome - case report by Antoaneta Dimitriva concluded that physiotherapy helps in functional improvement of the paretic extremities which is associated with gradual muscle strengthening and improved balance, gait and increasing movement speed. ${ }^{13}$ The study rehabilitation of the marathon runner with Guillain-Barre syndrome by Fisher TB, Stevens JE showed that after 3 weeks patient showed marked improvement in functional mobility as measured by functional independence measure scale. ${ }^{1}$ The study activation of shoulder girdle muscle during gripping task by Nazanin Nakhaie stated that muscle activation of proximal parts is necessary for distal activities proximal muscle provide stabilized and controlled base for distal parts activities. ${ }^{14}$

These results from statistical analysis of present study supported the alternative hypothesis which stated that subjects treated by proximal exercises improved distal muscle facilitation in post GBS individuals. As Proximal muscle strengthening including both $\mathrm{OKC}$ and $\mathrm{CKC}$ led to muscle strength improvement because they stimulated mechanoreceptors in and around the joint and increased muscle fiber, increased firing of muscle spindles and the number of motor units increased during these resistance exercises. ${ }^{24,25}$ In kinetic chain, muscle activation occurs in the muscle that crosses the moving joint, the overlapping segment is connected via joint and this create a system whereby movement at one joint produced or affected movement at another joint in kinetic link. ${ }^{26}$. So, we had seen improve the strength in distal muscles of upper limb and lower limb with proximal strengthening exercises GBS follows the pattern of demyelination / remyelination where clinical recovery follows remyelination at the spinal root level such that the first nerve segments to be demyelinated are the last to be remyelinated. ${ }^{27}$

Therefore, it is proven that interventions like proximal strengthening exercises shows better result with good prognosis in recovery of distal muscle facilitation.

\section{CONCLUSIONS}

The effect of proximal muscle strengthening is clinically significant on distal muscle facilitation and improves functional mobility in subjects with Guillain Barre Syndrome.

We acknowledge the guidance of Dean, Faculty of Physiotherapy, KIMSDU Karad, Dr. Suraj B. Kanase for constant support and Dr. Kakade SV, for helping us with statistical analysis.

Financial or Other Competing Interests: None.

\section{REFERENCES}

[1] Fisher TB, Stevens JE. Rehabilitation of a marathon runner with Guillain-Barre syndrome. J Neurol Phys Ther 2008;32(4):203-9.
[2] Meena AK, Jabeen SA. peripheral neuropathy. In: Munjal YP, Sharma SK, eds. API textbook of medicine. $10^{\text {th }}$ edn. Jaypee Brothers Medical Publishers 2015:2077-9.

[3] Arsenault NS, Vincent PO, Yu BHS, et al. Influence of exercise on patients with Guillain-Barré syndrome: a systematic review. Physiother Can 2016;68(4):367-76.

[4] Burns TM. Guillain-Barre syndrome. Semin Neurol 2008;28(2):152-67.

[5] Pitetti KH, Barrett PJ, Abbas D. Endurance exercise training in Guillain - Barre syndrome. Arch Phys Med Rehabil 1993;74(7):761-5.

[6] El Mhandi L, Calmels P, Camdessanché JP, et al. Muscle strength recovery in treated Guillain-Barré syndrome: a prospective study for the first 18 months after onset. Am J Phys Med Rehabil 2007;86(9):716-24.

[7] Todd JM, Davies PM. Cash's text book of neurology for physiotherapists. $4^{\text {th }}$ edn. Jaypee Brothers Medical Publishers 1993:267-95, 446.

[8] Khan F, Pallant JF, Amatya B, et al. Outcomes of high-and low-intensity rehabilitation programme for persons in chronic phase after Guillain-Barré syndrome: a randomized controlled trial. J Rehabil Med 2011;43(7):638-46.

[9] Khan F, Stevermuer TL, Simmonds FD. Rehabilitation for Guillain Barre Syndrome: analysis of the Australian rehabilitation outcomes dataset. Chinese Journal of Clinical Medicine and Research 2010;2(6):91-7.

[10] Khan F. Rehabilitation in Guillian Barre syndrome. Aust Fam Phys 2004;33(12):1013-7.

[11] Shah N, Shrivastava M, Kumar S, et al. Comparison of the outcomes of home based and supervised individually designed exercise programme amongst the patients in chronic phase after Guillain Barre Syndrome: study protocol for a randomized control trial. International Journal of Clinical Trials 2018;5(1):60-6.

[12] Umphred DA, Lazaro RT. Neurological rehabilitation. $6^{\text {th }}$ edn. Elsevier Health Sciences 2012: p. 386.

[13] Dimitrova A, Izov N, Maznev I, et al. Physical therapy and functional motor recovery in patient with Guillain-Barré Syndrome - case report. European Scientific Journal 2017;13(33):11-9.

[14] Nakhaie N, Nodehi-Moghadam A, Bakhshi E, et al. Activation of shoulder girdle muscles during gripping task: a systematic review of literature. PTJ 2014;4(1):3-8.

[15] Shah PJ, Kanase SB. Effect of intrinsic and extrinsic muscle training on quality of hand functions in stroke patients. Global Journal for Research Analysis 2018;7(3):42-4.

[16] Sawant VS, Kanase SB. Effect of conventional therapy and postioning with isometric shoulder exercises on functional shoulder subluxation in post stroke survivors. Indian Journal of Public Health Research and Development 2019;10(8):536-40.

[17] Vispute AR, Kanase SB. Effect of electrical stimulation, hot moist pack and exercises on shoulder hand syndrome in stroke patients. Global Journal for Research Analysis 2018;7(3):96-8.

[18] Hamilton GF, McDonald C, Chenier TC. Measurement of grip strength: validity and reliability of the sphygmomanometer and jamar grip dynamometer. J Orthop Sports Phys Ther 1992;16(5):215-9. 
[19] Martins JC, Teixeira-Salmela LF, Lara EM, et al. Validity and reliability of the modified sphygmomanometer test to assess strength of the lower limbs and trunk muscles after stroke. J Rehabil Med 2014;46(7):620-8.

[20] Alexandrescu R, Siegert RJ, Turner-Stokes L. Functional outcomes and efficiency of rehabilitation in a national cohort of patients with Guillain-Barré syndrome and other inflammatory polyneuropathies. PloS One 2014;9(11):e110532.

[21] O'Sullivan SB, Schmitz TJ, Fulk G. Physical rehabilitation. FA Davis Company 2014:324-5.

[22] Jain RS, Kookna JC, Srivastva T, et al. Guillain-barre Syndrome in Indian population: a retrospective study. J Assoc Physicians India 2019;67(4):56-9.

[23] Case-Smith J, Fisher AG, Bauer D. An analysis of the relationship between proximal and distal motor control. Am J Occup Ther 1989;43(10):657-62.
[24] Kim MK, Kong BS, Yoo KT. Effects of open and closed kinetic-chain exercises on the muscle strength and muscle activity of the ankle joint in young healthy women. J Phys Ther Sci 2017;29(11):1903-6.

[25] Lee NK, Kwon JW, Son SM, et al. The effects of closed and open kinetic chain exercises on lower limb muscle activity and balance in stroke survivors. Neuro Rehabilitation 2013;33(1):177-83.

[26] Ellenbecker TS, Davies GJ. Closed kinetic chain exercise: a comprehensive guide to multiple joint exercise. Human Kinetics Publishers Champaign 2001.

[27] Wexler I. Sequence of demyelination-remyelination in Guillain-Barre disease. J Neurol Neurosurg Psychiatry 1983;46(2):168-74. 